\title{
Reflection of $P^{\prime} P^{\prime}$ Seismic Waves from Discontinuities in the Mantle $^{1}$
}

\author{
James H. Whitcomb and Don L. Anderson \\ Seismological Laboratory, California Institute of Technology \\ Pasadena, California 91109
}

\begin{abstract}
A systematic study of the travel times and apparent velocities of precursors of the seismic core phase PKPPKP indicate that these phases are reflections from the mantle. The strongest reflection is from a depth of $630 \mathrm{~km}$. In order of confidence, other reflectors were found at depths of $280,520,940,410$ (very weak), and $1250 \mathrm{~km}$ (tentative). The weakness of the $410-\mathrm{km}$ reflection was surprising in view of the large velocity increase at this depth indicated by refraction and Love-wave studies. This transition region must be broader than the others or must involve a smaller density jump. Reflections were observed that were possibly from the top and bottom of the low-velocity zone at depths of 50 and $130 \mathrm{~km}$, respectively. The above reflections are interpreted in terms of the following solid-solid phase changes, in order of increasing depth: pyroxene-garnet solid solution, olivine $\rightarrow \beta$ spinel, $\beta$ spinel $\rightarrow$ spinel and pyroxene $\rightarrow$ spinel + stishovite, spinel $\rightarrow$ post-spinel, and garnet $\rightarrow$ ilmenite or oxides. A spin-spin transition in $\mathrm{Fe}^{2+}$ may be responsible for one of the deeper discontinuities found by others.
\end{abstract}

Recent models of the structure of the upper mantle, such as those of Anderson and Toksöz [1963], Niazi and Anderson [1965], Archambeau et al. [1969], Johnson [1967], Ibrahim and Nuttli [1967], Green and Hales [1968], Julian and Anderson [1968], and Anderson and Julian [1969] include regions of high velocity gradient in the upper mantle. The sharpness of these discontinuities has led to new interest in looking for reflections of seismic waves from structure in the upper mantle Whitcomb and Anderson [1968], and Niazi [1969] found reflections from the upper surfaces of discontinuities in the upper mantle. Another reflection of interest is the reflection of $P^{\prime} P^{\prime}$ (PKPPKP) from the underneath surface of discontinuities. This reflection has the decided advantage of being in a quiet part of the seismic record before the main $P^{\prime} P^{\prime}$ phase. Gutenberg [1960] noted arrivals up to 30 sec before $P^{\prime} P^{\prime}$, and Adams [1968] interpreted $P^{\prime} P^{\prime}$ precursors as reflections arriving up to $70 \mathrm{sec}$ before the main phase. Because Adams was using isolated

\footnotetext{
${ }^{1}$ Contribution 1711, Division of Geological Sciences, California Institute of Technology.
}

Copyright (C) 1970 by the American Geophysical Union. stations for reading the precursors, he could not recognize that some of his readings for the deep earthquakes were probably $S K K K P$, which, as Engdahl and Flinn [1969a] have pointed out, has a different apparent slowness. However, Adams' remaining readings indicated discontinuities near 65 to $70 \mathrm{~km}$ and 160 to $180 \mathrm{~km}$ in depth. Engdahl and Flinn [1969b] found a precursor with the proper apparent slowness corresponding to a reflection depth of $650 \mathrm{~km}$. Our notation is similar to that used by Bolt et al. [1969], who designated a reflection of the $P P$ phase at a depth $d$ in kilometers as $P d P$, in that $P^{\prime} d P^{\prime}$ is used to indicate a reflection of the $P^{\prime} P^{\prime}$ phase at depth $d$ in kilometers. Thus, a reflection at $650 \mathrm{~km}$ would be $P^{\prime} 650 P^{\prime}$, and $P^{\prime} 0 P^{\prime}$ is equivalent to $P^{\prime} P^{\prime}$.

Seismic records were searched systematically for $P^{\prime} P^{\prime}$ precursors up to five minutes before the main phase and were analyzed for reflectors at depth. Two geographic regions of reflection are studied, one near the Atlantic-Indian rise south of the tip of Africa and the second near the Ninety-East ridge in the Indian Ocean. The wide aperture of the CIT array in southern California helps to confirm the arrivals as $P^{\prime} P^{\prime}$ reflections and to investigate lateral variations in the reflection surfaces. 


\section{Collection and Reduction of Data}

Apparent wave slowness is an important criterion for the identification of $P^{\prime} P^{\prime}$ precursors as mantle reflections, because it is negative and very small, 2 to $4 \mathrm{sec} / \mathrm{deg}$. To take advantage of this characteristic, we used the California Institute of Technology seismometer array in southern California, the Tonto Forest array in Arizona, and the array of the University of California at Berkeley in central California. The following stations were used:

Southern California: BAR, CLC, CWC, FTC, GLA, GSC, HAY, ISA, KRC, MWC, PAS, PLM, RVR, SBC, SCI, SNC, SYP, TIN, WDY

Northern California: ARC, BKS, FRE, JAS, MHC, MIN, ORV, PRI.

Tonto Forest: TFO.

Only short-period, vertical seismometer records were read.

Earthquakes from the northern part of the Japanese arc, designated group 1, and South America, designated group 2, were used; both areas are approximately $70^{\circ}$ from Pasadena, near the $P^{\prime} P$ ' caustic, where largest amplitudes are expected, and both areas have deep earthquakes. In general, deep earthquakes are most satisfactory for $P^{\prime} P^{\prime}$ studies because of their characteristic short $P$-wave coda and lack of interfering surface waves. It is found that magnitudes greater than 6.0 are needed for useful amplitudes of $P^{\prime} P^{\prime}$ and precursors. Table 1 shows the descriptive data taken from the USCGS bulletins for the earthquakes of group
1 and group 2 and the epicentral distances to PAS. $P$-wave residuals at southern California stations are $<1$ sec.

The periods of the $P^{\prime} P^{\prime}$ arrivals and precursors are generally in the range 1.5 to 3.0 sec on the Benioff short-period vertical seismometers. Waves with periods as short as 1 sec and as long as 5 sec are seen, however. No systematic difference in period is noted between the main branches of $P^{\prime} P^{\prime}$ and the early arrivals, and all arrivals from the same earthquake tend to have similar periods in this distance range.

Records from the various stations were read independently without reference to each other or to a travel-time scale, and all the readings were made by the authors in an effort to be completely systematic. The readings of $P^{\prime} P^{\prime}$ and precursors were read to the nearest second and were graded according to the following scale:

3. Sharp pulse or a wave train with a sharp beginning.

2 Emergent beginning but a definite signal, usually a wave train.

1 Small wave train with an emergent beginning; character (difference in period or amplitude) distinguishes it from the prevailing noise level.

In order to compare the $\mathrm{P}^{\prime} \mathrm{P}^{\prime}$ data from different earthquakes, corrections must be made for the earth's ellipticity and the focal depth of the earthquake in order to put the origin at the surface of a standard spherical earth. The epicentral depth correction depends on

TABLE 1. Earthquakes and Epicentral Distance to PAS

\begin{tabular}{|c|c|c|c|c|c|c|c|c|c|}
\hline No. & Date & ${ }_{\mathrm{h}}^{\mathrm{O}}$ & $\begin{array}{r}\operatorname{gin} \\
\mathrm{m}\end{array}$ & ime, & Latitude, & Longitude, & $\begin{array}{c}\text { Depth, } \\
\text { km }\end{array}$ & Magnitude & $\begin{array}{c}\text { Delta, } \\
\text { deg }\end{array}$ \\
\hline \multicolumn{10}{|c|}{ Group 1. Epicenters, Japanese Arc; Reflections, Atlantic-Indian Rise } \\
\hline 1 & May 31,1964 & 00 & 40 & 36.4 & $43.5^{\circ} \mathrm{N}$ & $146.8^{\circ} \mathrm{E}$ & 48 & 6.3 & 70.71 \\
\hline 2 & June 23,1964 & 01 & 26 & 37.0 & 43.3 & 146.1 & 77 & 6.2 & 71.25 \\
\hline 3 & June 11,1965 & 03 & 33 & 44.9 & 44.7 & 148.7 & 47 & 6.0 & 68.94 \\
\hline 4 & Oct. 25,1965 & 22 & 34 & 24.3 & 44.2 & 145.3 & 180 & 6.2 & 71.32 \\
\hline 5 & Jan. 29,1968 & 10 & 19 & 05.6 & 43.6 & 146.7 & 40 & 7.0 & 70.73 \\
\hline \multicolumn{10}{|c|}{ Group 2. Epicenters, South America; Reflections, Ninety-East Ridge } \\
\hline 6 & Nov. 3, 1965 & 01 & 39 & 02.5 & $9.1 \% \mathrm{~S}$ & $71.4^{\circ} \mathrm{W}$ & 583 & 6.2 & 61.76 \\
\hline 7 & May 11, 1967 & 15 & 05 & 16.8 & 20.3 & 68.5 & 67 & 6.1 & 71.88 \\
\hline 8 & Sept. 3, 1967 & 21 & 07 & 30.8 & 10.6 & 79.8 & 38 & 6.5 & 57.51 \\
\hline 9 & Dec. 21,1967 & 02 & 25 & 21.6 & 21.8 & 70.0 & 33 & 6.3 & 72.08 \\
\hline 10 & Dec. 27,1967 & 09 & 17 & 55.7 & 21.2 & 68.3 & 135 & 6.4 & 72.67 \\
\hline 11 & June 19, 1968 & 08 & 13 & 35.0 & 5.6 & 77.2 & 28 & $6.4-6.9$ & 55.31 \\
\hline
\end{tabular}


which branch of $P^{\prime} P^{\prime}$ is being considered because each branch has, in general, a different apparent slowness.

The most recent published studies of the branches of $P$ have been made by Adams and Randall [1964] and Bolt [1968], which differ somewhat in the $P^{\prime}$ range of $142^{\circ}$ to $152^{\circ}$ considered here. Doubling the time and distance data of $P^{\prime}$ gives the equivalent values for $P^{\prime} P^{\prime}$ branches. $P^{\prime} P^{\prime}$ arrival-time data are compared with the branches of Adams and Randall and Bolt in Figure 1. Simple reflectivity calculations for velocity models from the Ninety-East ridge [Francis and Raitt, 1967] show that the reflections of significant amplitude are expected up to 5 sec before the calculated $P^{\prime} P^{\prime}$ surface reflection time, and the maximum amplitude of the $P^{\prime} P^{\prime}$ phase is not from the air-water surface reflection but from the ocean-bottom reflection. Therefore, the $P^{\prime} P^{\prime}$ phase is expected to be more complicated than the $P^{\prime}$ phase on which the models are based. This effect is seen in Figure 1. The Adams and Randall model is chosen for reducing the data because the times, and especially amplitudes predicted for their strongest phases, most closely agree with the data of Figure 1.
Adams and Randall [1964] designated the $P^{\prime}$ branches as $P_{A B}^{\prime}, P_{D F}^{\prime}, P_{G H}^{\prime}$, and $P^{\prime}{ }_{L I}$ (not shown). The corresponding $P^{\prime} P^{\prime}$ branches are $P^{\prime}{ }_{B B} P^{\prime}{ }_{A B}$, etc. For epicentral distances between $55^{\circ}$ and $70^{\circ}$, the most prominent phase is $P^{\prime}{ }_{W H} P_{G I I}^{\prime}$, (apparent slowness is $2.3 \mathrm{sec} / \mathrm{deg}$ ), which arrives between $P_{D P}^{\prime} P_{D F}^{\prime}$, the earliest phase, and $P_{A L}^{\prime} P_{A B}^{\prime} . P_{I J}^{\prime} P_{I J}^{\prime}$ arrives close after $P^{\prime}{ }_{G H} P_{G I I}^{\prime}$, and because it is small it is not important in this range. For epicentral distances between $70^{\circ}$ and $75^{\circ}, P_{D P}^{\prime} P_{D F}^{\prime}$ (apparent slowness is $1.6 \mathrm{sec} / \mathrm{deg}$ ) is the most prominent phase and arrives after the smaller $P_{I J}^{\prime} P_{I J}^{\prime}$ and $P_{G I I}^{\prime} P_{G I I}^{\prime}$. All phases have arrival times within about 3 sec of each other near the focal point, $70^{\circ}$.

The NTS-NE $P$-wave-velocity model of $J u$ lian and Anderson [1968], similar to that of Johnson [1967], is used to calculate the epicentral distance and time corrections in order to correct $P^{\prime} P^{\prime}$ and the precursors for focal depth. The time correction is always added, and the distance correction lengthens the longer part of the great circle path, thus decreasing the direct epicentral distances. Because the reflections are assumed to come from the largest amplitude branch for that epicentral distance,

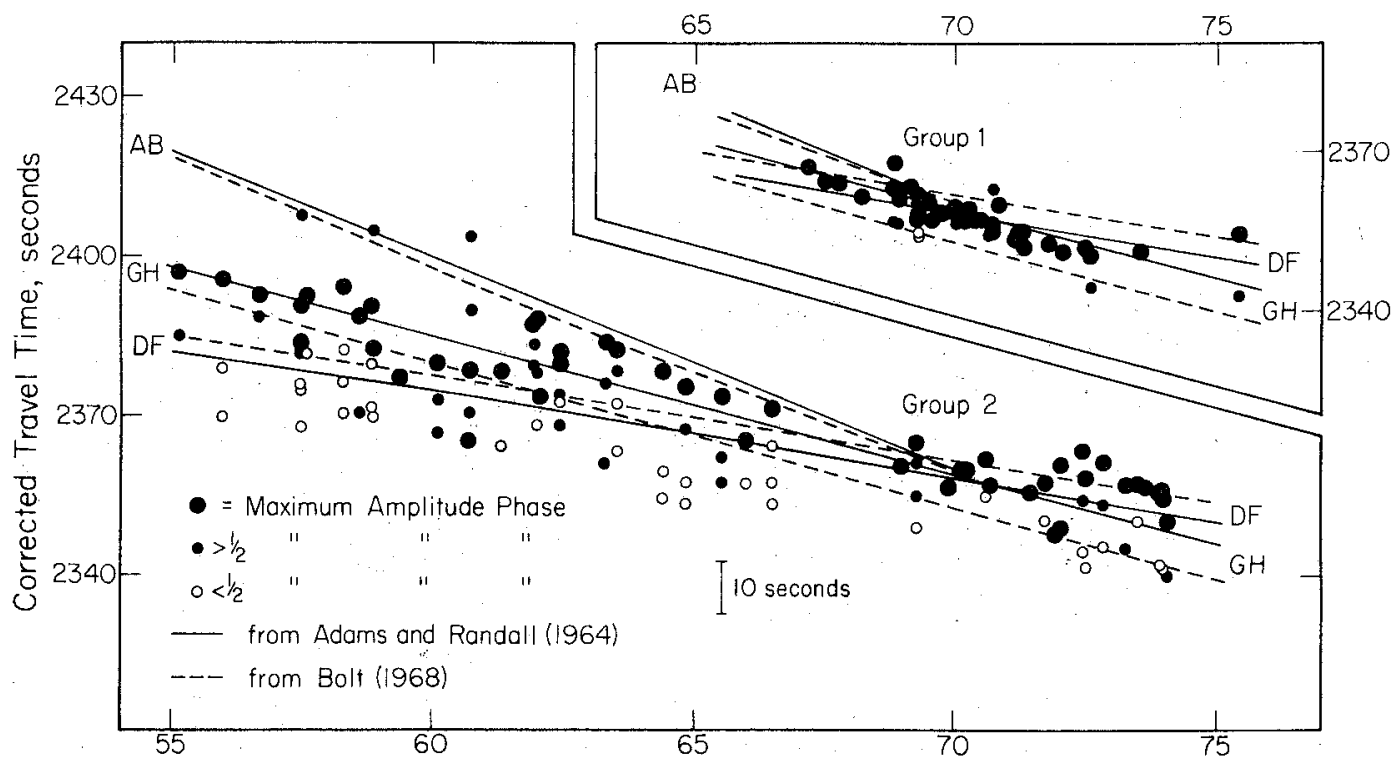

Corrected Epicentral Distance, degrees

Fig. 1. Comparison of $P^{\prime} P^{\prime}$ arrival times and amplitudes with the branches of Adams and Randall [1964] and Bolt [1968]. 
the focal depth corrections are based on the $G H$ branch for epicentral distances $55^{\circ}$ to $70^{\circ}$ and on the $D F$ branch for epicentral distances greater than $70^{\circ}$. The upper-mantle reflections from horizontal layering have almost the same apparent velocity as the main branch, and the corrections apply to both. This is not strictly accurate near the $P^{\prime} P^{\prime}$ focus at $70^{\circ}$, because a $G H$ branch reflection at depth does not follow the same ray path as the $G H$ branch surface reflection measured at the same epicentral distance. That is, a $P^{\prime} d P^{\prime}$ wave has the same ray path as a $P^{\prime} P^{\prime}$ wave of longer great circle distance (shorter epicentral distance); for a $P^{\prime} 650$ $P^{\prime}$ wave seen at $60^{\circ}$, the ray path would correspond to that of $P^{\prime} P^{\prime}$ at about $58^{\circ}$. Therefore, an error is expected in the focal depth corrections for deep reflection data around $72^{\circ}-$ $73^{\circ}$ epicentral distance. However, this error involves only a few points and is less than $1 / 2$ sec.

The geographic areas of $P^{\prime} P^{\prime}$ reflection are

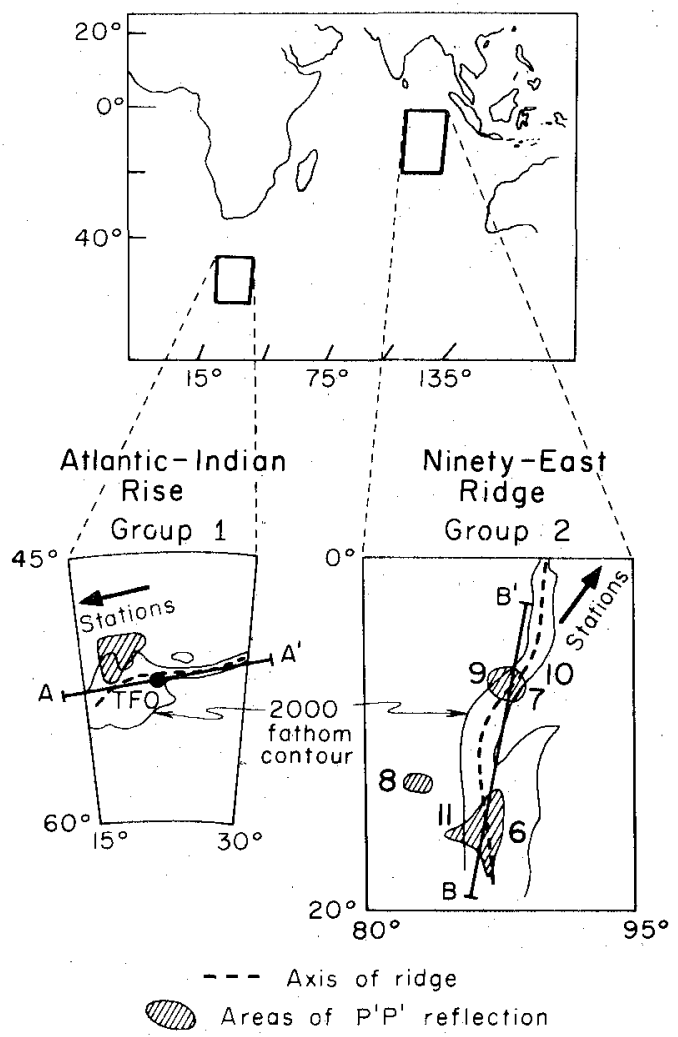

Fig. 2. Map of $P^{\prime} P^{\prime}$ reflection areas. calculated from the corrected epicentral distance for a surface focus and are shown in Figure 2. $P^{\prime} P^{\prime}$ from group 1 (Hokkaido region) reflects near the Atlantic-Indian rise south of Cape Good Hope. This rise' is a classical ocean-floor spreading structure and is the continuation of the mid-Atlantic rise into the Indian Ocean, where it connects with the mid-Indian rise. $P^{\prime} P^{\prime}$ waves from group 2 (Peru, Bolivia, and Chile) reflect at the Ninety-East ridge in the northeast central Indian Ocean. Study of this ridge [Francis and Raitt, 1967; Le Pichon and Heirtzler, 1968] indicates that it is not a source of ocean-floor spreading but that it is some type of compressional feature with a thickening of the crust under the ridge. Distribution of the reflection points perpendicular to the axes of the ridges extends about $3^{\circ}$ north of the Atlantic-Indian rise and about $5^{\circ}$ west of the Ninety-East ridge as seen in Figure 2.

Once the reflecting branch has been chosen on the basis of maximum $P^{\prime} P^{\prime}$ amplitude, the reflection lead time from the main $P^{\prime} P^{\prime}$ branch from the Adams and Randall [1964] $P^{\prime}$ model can be used to calculate the depth of reflection from the NTS-NE velocity model [Julian and Anderson, 1968]. However, the epicentral distance separating the use of the $D F$ branch or the $G H$ branch $\left(70^{\circ}\right.$ for near-surface reflections) must be shifted to greater epicentral distances for deeper reflection depths in order to preserve equivalent ray paths as mentioned above. For example, the division is at about $72^{\circ}$ for $P^{\prime} 650 P^{\prime}$. Thus, at epicentral distances less than $72^{\circ}, P^{\prime} 650 P^{\prime}$ should have an apparent slowness of $2.3 \mathrm{sec} / \mathrm{deg}$, corresponding to the $G H$ branch, and beyond $72^{\circ}$ a slowness of 1.6 sec/deg, corresponding to the $D F$ branch.

A basic assumption in the analysis is that the earth, especially the core and reflecting layers in the upper mantle, is spherically symmetric. The approximately \pm 1 -sec scatter of $P^{\prime}$ branch data [Adams and Randall, 1964, and Bolt, 1968] gives some idea of reading accuracy and the asymmetry of the earth's core and leads to the conclusion that $P^{\prime} P^{\prime}$ and $P^{\prime} d P^{\prime}$ readings are not more significant than \pm 1 sec at best. The assumption that the reflecting layers are spherically symmetric is not too bad, because amplitudes of $P^{\prime} P^{\prime}$ are largest near $70^{\circ}$. Thus, if reflecting layers are dipping just a few degrees, at least one of the $P^{\prime}$ legs cannot travel in a 
large-amplitude path because its $d t / d \Delta$, or seismic parameter, is changed. Because of this amplitude effect, only reflections from nearhorizontal layers will tend to be seen.

Figure 3 shows examples of $P^{\prime} P^{\prime}$ and the precursors from events $2(\mathrm{TFO})$ and 6 . (CWC, WDY). The confidence codes and calculated reflection depths are shown for precursor readings on the records, along with the $P^{\prime} P^{\prime}$ main branch times from Adams and Randall [1964].

Because of the systematic reading of all phases on the record, it is necessary to identify as many as possible of the phases other than $P^{\prime} P^{\prime}$ and $P^{\prime} d P^{\prime}$ and to eliminate them from analysis. $S K K K P$, a phase identified by Engdahl and Flinn [1969a], is prominent in the recordings of event 6 (Figure 3 ), and its apparent slowness of $4.4 \mathrm{sec} / \mathrm{deg}$ easily separates it from the $P^{\prime} P^{\prime}$ and precursor readings, as is shown in the timedistant plot for event 6 in Figure 4. The nearsource surface reflection of $P^{\prime} P^{\prime}\left(p P^{\prime} P^{\prime}\right)$ is seen and is eliminated in a number of records; except in event $2, p P^{\prime} P^{\prime}$ is significantly smaller than the main phase $P^{\prime} P^{\prime}$. In event 2 (a sample record is shown in Figure 3 ), the phase $p P^{\prime} P^{\prime}$ is large with respect to the $P^{\prime} P^{\prime}$ phase, and this leads to an ambiguity in identifying a precursor as $p P^{\prime} d P^{\prime}$ or $P^{\prime} d P^{\prime}$. If both occur as reflections from a given depth, then the time difference between the $p P^{\prime} P^{\prime}$ and $P^{\prime} P^{\prime}$ phases should be the same as between $p P^{\prime} d P^{\prime}$ and $P^{\prime} d P^{\prime}$, and this possibility arises in event 2 . The event 2 precursors designated with a depth of 534 and 503 $\mathrm{km}$ (Figure 3 ) could be the $p P^{\prime} P^{\prime}$ reflections from 656 and $618 \mathrm{~km}$ that are seen approximately 23 sec earlier, the proper $P^{\prime} P^{\prime}-p P^{\prime} P^{\prime}$ time interval for $77-\mathrm{km}$ focal depth. This ambiguity is discussed later in the light of the remaining events.

\section{Discussion of Results}

Figure 5 shows time-distance plots for group 1 (reflecting at the Atlantic-Indian rise) and group 2 (reflecting at the Ninety-East ridge). Special symbols indicate the event and confidence for each data point, and all identifiable phases other than the $P^{\prime} P^{\prime}$ and $P^{\prime} d P^{\prime}$ have been omitted. The $A B, G H$, and $D F$ main branches of Adams and Randall [1964] are also shown.

Figure 6 shows the same data reduced to their equivalent reflection depths. The depths are plotted as a function of perpendicular distance (in degrees on a spherical earth) from a reference great circle line designated by $A-A^{\prime}$ and
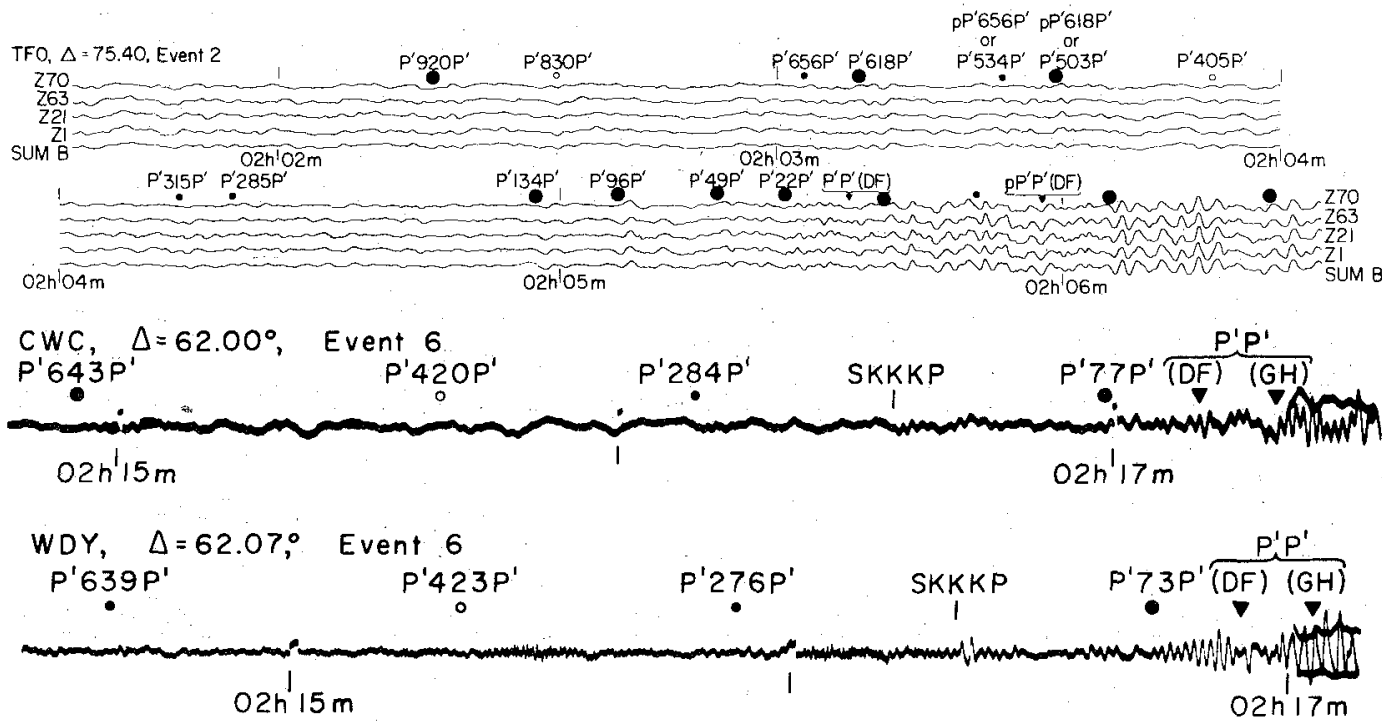

- High -

- Medium -

- Low Confidence Reading

v Theoretical Times

Fig. 3. Short-period vertical records of $P^{\prime \prime} P^{\prime}$ and precursors from events 2 (TFO) and 6 (CWC, WDY) with coded readings and main branch times from Adams and Randall [1964]. Station corrections are TFO, $0 \mathrm{sec;}$ CWC, $12.7 \mathrm{sec}$; WDY, $29.4 \mathrm{sec}$. 


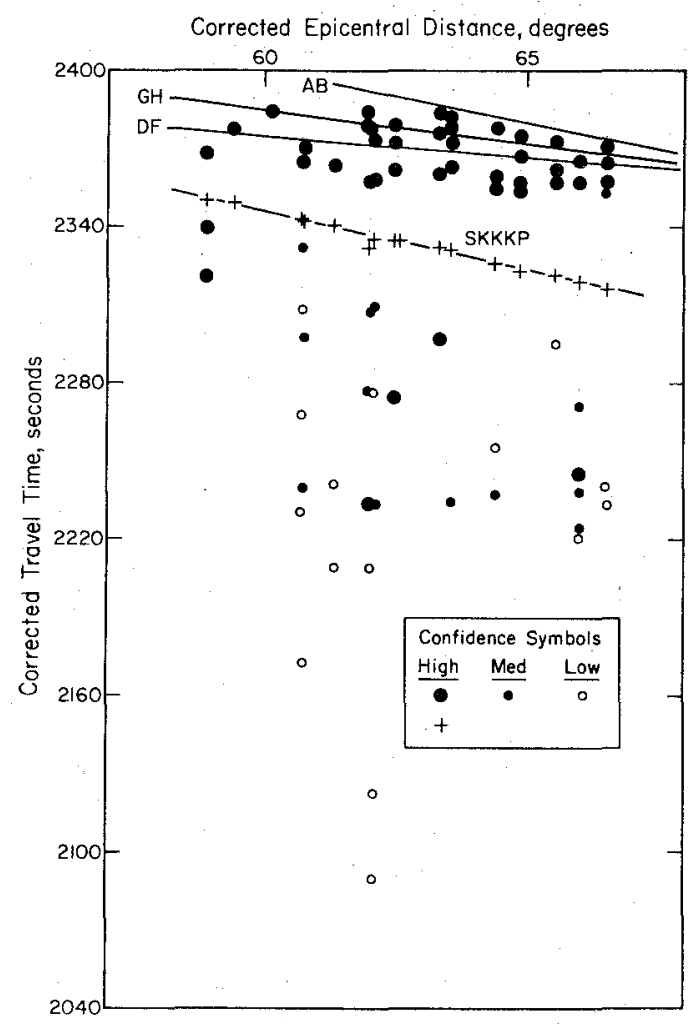

Fig. 4. The $S K K K P$ phase and the $P^{\prime} P^{\prime}$ main branches for event 6 . The $P^{\prime} P^{\prime}$ data are from Adams and Randall [1964].

$B-B^{\prime}$ in Figure 2 for groups 1 and 2, respectively.

Figure 6 also includes histograms of the depth data formed by summing the weights of the data for $20-\mathrm{km}$ intervals. The histograms give an indication of the strength and significance of reflecting layers if the layers are horizontal' and if the $P^{\prime} d P^{\prime}$ phase has the proper apparent slowness. The correct wave slowness assumption is seen at the onset of the data in Figure 5 at $65^{\circ}, 660 \mathrm{~km}$ for groups 1 and 2. Very few points are seen immediately below, thus making the onset sharp and significant, the correct slowness being $2.3 \mathrm{sec} / \mathrm{deg}$. This significance is seen at the histogram peaks near $650 \mathrm{~km}$ for both areas. The group 1 data at the interval $490-540 \mathrm{~km}$ in Figure 5 also show a good example of the proper apparent slowness with very little scatter.

On the basis of the depth plots and histogram distribution of Figure 6, intervals inter- preted as zones of reflection are determined and are shown in Table 2 and in Figures 5 and 6 às shaded zones. To facilitate discussion, the zones in Table 2 are given designations of 280 , $410,520,630$, and $940 \mathrm{~km}$. The 410 zone for group 1 is questionable and is included only for comparison with the 410 zone for group 2, which is only of fair significance. These intervals are considered to be weakly reflective and definitely not as significant as the other reflection zones.

Table 2 shows that the zones below $500 \mathrm{~km}$ in group 2 (Ninety-East ridge) are consistently deeper by about $20 \mathrm{~km}$ (a 4-sec time shift) than those of group 1 (Atlantic-Indian rise). In order to determine whether this shift is real, it is necessary to analyze other possible causes for a uniform time difference of about 4-sec between the groups. The signals are read to the nearest second, and errors in the calculated corrections could add up to no more than about $0.5 \mathrm{sec}$ (assuming no consistent error in focal depth determinations). The human errors of reading the beginning of an arrival are difficult to evaluate, but because records for both groups were read in a consistent, systematic manner, no comparative time shift between the groups should result. Therefore, the 4 -sec time shift should not result from reading or correction errors. Because theoretical main $P^{\prime} P^{\prime}$ branch times for both groups are assumed in depth calculations, a difference in velocity structure between the two main areas could give the 4 -sec or $20-\mathrm{km}$ difference. This could be done by a higher velocity along the group 2 ray paths, but this should be seen as earlier mainbranch arrivals. Inspection of Figure 1 shows that, if anything, the main-branch arrivals of group 2 are at the same time or later than those of group 1. Therefore, if the 4-sec time shift is caused by velocity differences, the group 2 (Ninety-East ridge) ray-path velocities below $1000 \mathrm{~km}$ would have to be higher, and above about $400 \mathrm{~km}$ would have to be lower than corresponding velocities of group 1 (AtlanticIndian rise). If this difference in shallow velocities is spread out between $400 \mathrm{~km}$ and the surface, it would require that velocities under the Ninety-East ridge be an average of about $4 \%$ lower than velocities under the AtlanticIndian rise from 0 to $400 \mathrm{~km}$.

Analysis of the 4-sec shift between groups 1 
and 2 data leads to two possibilities: (1) group 2 (Ninety-East ridge) velocity is lower above $400 \mathrm{~km}$ and higher along the $P^{\prime} P^{\prime}$ ray below $1000 \mathrm{~km}$ than group 1 velocity; or (2) group 2 layers below $400 \mathrm{~km}$ are deeper by about 20 $\mathrm{km}$ than those of group 1. Both differences can be caused by differences in $(a)$ temperature or (b) chemical composition at the two areas. Combining the two effects with the two causes leads to four combinations of cause and effect. Although it is difficult to make a choice, some simple implications can be noted. If the temperature-velocity combination 1 a dominates, it requires a higher upper-mantle temperature under the Ninety-East ridge, which is not a center of ocean-floor spreading, than that under the Atlantic-Indian rise; this contradicts mantle models with the oceanic rises as upwelling, hightemperature areas. If the temperature-depth combination $2 a$ dominates and temperatures under the Atlantic-Indian rise are higher, then the phase-change equilibrium curves below about $500 \mathrm{~km}$ must have negative slopes, as do those given by Anderson [1967], because the AtlanticIndian reflectors are shallower. For the $2 b$ combination, a possible chemical compositional difference is suggested by the proposal of Anderson [1967] for an increase in iron or $\mathrm{Fe}_{2} \mathrm{SiO}_{4}$ content with depth, If this is true and if more vertical movement is occurring at the Atlantic-Indian rise than at the Ninety-East ridge, it is natural to expect a higher iron content under the rise. There are no direct data to indicate the effect of varying $\mathrm{Fe}$ content on phase changes below $500 \mathrm{~km}$. However, if the deeper phase changes are assumed to behave as the olivine-spinel $(\mathrm{Mg}, \mathrm{Fe})_{2} \mathrm{SiO}_{4}$ solid-solution phase change at about $350 \mathrm{~km}$ [Ringwood, 1969], an increase in iron content of about $8 \%$ under the AtlanticIndian rise would raise the spinel to post-spinel phase change by the needed $20 \mathrm{~km}$.

Lateral variation and ease of interpretation divide the data into three depth groups: above $50 \mathrm{~km}, 50$ to $250 \mathrm{~km}$, and below $250 \mathrm{~km}$.

Above $50 \mathrm{~km}$. Structures above $50 \mathrm{~km}$ are seen in both groups 1 and 2 , but the computation of depth is complicated by lateral variations in velocity, which are known to be considerable [e.g., Francis and Raitt, 1967]. In some parts of the time-distance plots, it is diffcult to locate the $P^{\prime} P^{\prime}$ main phase, as, for example, in the oscillation of group 2 data about the theoretical main $P^{\prime} P^{\prime}$ branch and splitting of data points beyond $70^{\circ}$ epicentral distance in Figure 5. This splitting of data around the main $P^{\prime} P^{\prime}$ branch is believed to be caused by lateral velocity changes in the crust or near-crustal layers. However, it may be a variation of the $P^{\prime} P^{\prime}$ main branch which is not well known in this range. Correlation with detailed bathymetry and sedimentation depths at the reflection point and delineation of the $P^{\prime}$ times and amplitudes near the $P^{\prime}$ focus is necessary to resolve the shallow structure above 50 $\mathrm{km}$.

50 to $250 \mathrm{~km}$. In the range of $50-250 \mathrm{~km}$, group 1 data (Atlantic-Indian rise) in Figure 6 show a strong $50-\mathrm{km}$ reflection to the north which is lost or is thinning going south toward the ridge. The data on line $A-A^{\prime}$ from TFO event 2 , whose reflection point is east (Figure 2) of the other near-ridge points, gives a $50-\mathrm{km}$ point again. The reflector at $50 \mathrm{~km}$ is probably the top of the low-velocity zone, which is predicted to be a very sharp change in velocity by Spetzler and Anderson [1968] and Anderson and Sammis [1969] because of partial melting. A strong reflection near $130 \mathrm{~km}$ is indicated by the depth plot and histogram, with few points below until $260 \mathrm{~km}$. The onset of data at 130 $\mathrm{km}$ may be the bottom of the low-velocity zone.

Group 2 data (Ninety-East ridge) between 50 and $250 \mathrm{~km}$ vary laterally even more than those of group 1. A strong reflector is seen at 60 to $70 \mathrm{~km}$ under the ridge axis $\left(B-B^{\prime}\right.$ in Figure 2) which extends to the west only about $0.5^{\circ}$ and is not seen as sharply thereafter. Five degrees to the west, a reflector is seen at $100 \mathrm{~km}$ and appears to deepen to about $200 \mathrm{~km}$, but the distribution is rather complex. The structure here is probably related to the Ninety-East ridge's being a compressional feature in the 'new global tectonics' sense.

Below $250 \mathrm{~km}$. For both group 1 and group 2 (Figure 6), the reflecting zones below $250 \mathrm{~km}$ in order of confidence and strength are: 630, $280,520,940$, and $410 \mathrm{~km}$ (very weak). These zones do not seem to change depth laterally, except for the $280-\mathrm{km}$ zone in group 1 (AtlanticIndian rise), which may deepen somewhat to the south.

The $630-\mathrm{km}$ zone is the most readily identifiable because it is the first strong reflector. This confirms the discontinuity first found from sur- 
face-wave studies [Anderson and Toksöz, 1963] and confirmed by recent $P$-wave velocity studies [Niazi and Anderson, 1965; Lewis and Meyer, 1968; Green and Hales, 1968; Archambeau et al., 1969; Johnson, 1967; Julian and Anderson, 1968; Anderson and Julian, 1969; Ibrahim and $N u t t l i, 1967]$, and the same $P^{\prime} 650 P^{\prime}$ reflection was found by Engdahl and Flinn [1969b] (one of their sources was event 2).

The $280-\mathrm{km}$ zone is also easily identifiable by its high density of readings adjoining zones of few or no data points (Figure 6). A zone of anomalous change at or near $280 \mathrm{~km}$ is absent in the recent $P$-wave velocity models. This apparent conflict could be due to (1) a sharp change in density (thus increasing the acoustic impedance, a function of density times $P$-wave velocity) but little change in $P$-wave velocity near $280 \mathrm{~km}$, or (2) the upper mantle near 280 $\mathrm{km}$ in continental areas, where the detailed $P_{-}$ wave velocity work was done, is thermally or chemically different from that for the oceanic areas in this study.

The data for the $520-\mathrm{km}$ zones in groups 1 and 2 appear almost as strong as the 630- and $280-\mathrm{km}$ zones, but the interpretation is clouded by the possibility that this data might be $p P^{\prime} 630 P^{\prime}$, which would arrive about 23 sec after $P^{\prime} 630 P^{\prime}$ for an event with $77-\mathrm{km}$ focal depth (event 2, Figure 3). There are eight events with focal depths less than $100 \mathrm{~km}$ ranging from 28 to $77 \mathrm{~km}$, but only one, event 2 , has a $p P^{\prime} P^{\prime}$ that is as large as $P^{\prime} P^{\prime}$ (Figure 3 ). If the data interpreted as $P^{\prime} d P^{\prime}$ from, say, $500 \mathrm{~km}$ are really $p P^{\prime} d P^{\prime}$ from $650 \mathrm{~km}$, it is difficult to explain why the $520-\mathrm{km}$ zone has better definition and less scatter than the $630-\mathrm{km}$ zone in Figures 5 and 6 (group 1). The $520-\mathrm{km}$ zone should have more scatter, because the focal depth range 28 to $77 \mathrm{~km}$ would have a range of $P^{\prime} d P^{\prime}$ to $p P^{\prime} d P^{\prime}$ differences of about 10 to 23 sec. Further, no equivalent $p P^{\prime} d P^{\prime}$ reflection is seen corresponding to the $280-\mathrm{km}$ zone which, by these data, is as reflective as the $630-\mathrm{km}$ zone of group 1. Thus, it is concluded that the $520 \mathrm{~km}$ reflecting zones of groups 1 and 2 are real. A velocity discontinuity at $520 \mathrm{~km}$ is also absent in the recent $P$-wave velocity models, but Hoffmann et al. [1961] found a reflection from $520 \mathrm{~km}$ to be one of their strongest in quarryblast reflection studies of the upper mantle in Utah.

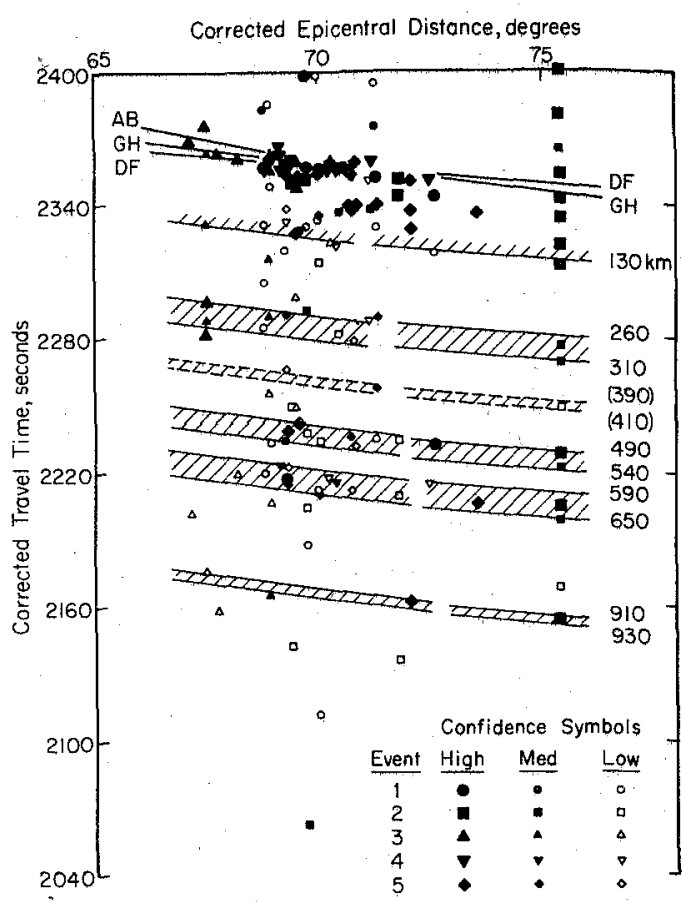

Fig. 5. Time-distance plots for (above) group 1 , reflecting at the Atlantic-Indian rise, and (right) group 2, reflecting at the Ninety-East ridge. $P^{\prime} P^{\prime}$ main branch times are from Adams and Randall [1964].

The $940-\mathrm{km}$ zones in groups 1 and 2 are based on fewer points than the shallow discontinuities, but the lateral coherence of the data and absence of medium and high confidence data for intervals of $260 \mathrm{~km}$ above and $270 \mathrm{~km}$ below the zones make them stand out (Figure $5)$. The $P$-wave velocity models of Archambeau et al. [1969] and Johnson [1969] include a discontinuous increase in velocity at about $970 \mathrm{~km}$, and Hoffmann et al. [1961] found a strong reflection at $910 \mathrm{~km}$.

Only a weak indication of the $410-\mathrm{km}$ zone is seen in group 2 data (Ninety-East ridge), and it is definitely not as strong a reflector as the $630-\mathrm{km}$ zone. This conflicts with the $P$ wave velocity models of Archambeau et al. [1969], Johnson [1967], and Julian and Anderson [1968] and with the $P d P$ reflection results of Bolt et al. [1969], who found a strong 400$\mathrm{km}$ layer but no $630-\mathrm{km}$ layer. It is possible that the $400-\mathrm{km}$ discontinuity is weaker or absent in an oceanic compared to a continental mantle, or that it is not as sharp as the other 


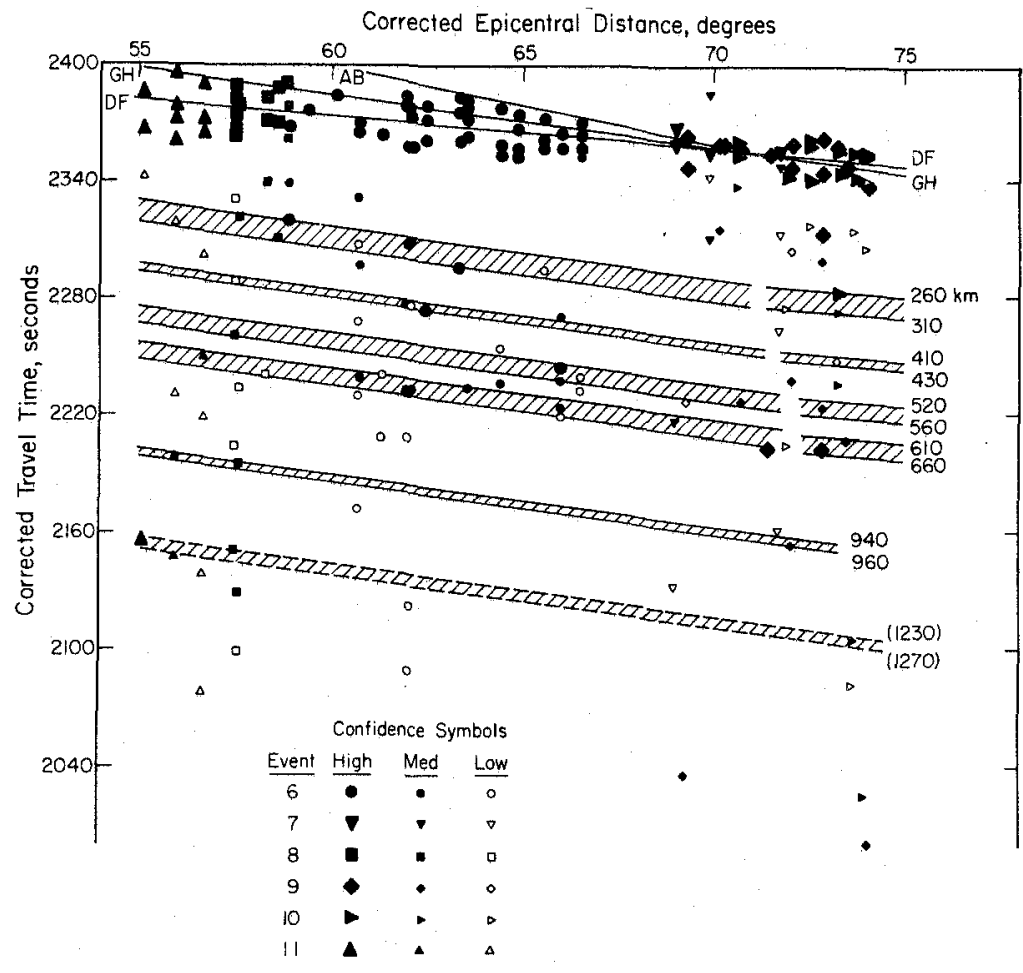

Fig. 5 .

discontinuities that produce strong $P^{\prime} d P^{\prime}$ reflections. It may be a broader transition.

Below the $940-\mathrm{km}$ zone, the only significant data are from group 2. Figure 5 shows a dashed depth zone near $1250 \mathrm{~km}$ for group 2, but, because group 1 has no points near this time, it is not interpreted as a reflector. However, Johnson's [1967] structure has a small discontinuity near $1230 \mathrm{~km}$.

The amplitude and period of reflections can give quantitative information on the sharpness of the reflecting zones. However, the problem is complicated by scatter of $P^{\prime} P^{\prime}$ data and lack of information on shallow-velocity structure at the reflecting site and the amplitude of the main $P^{\prime}$ branches and their lateral variations. A hypothetical first-order discontinuity model can be made in order to get some feeling for what amplitudes to expect, especially for a combination of reflectors. Table 3 illustrates a model that is typically oceanic above $12 \mathrm{~km}$ and has first-order discontinuities whose sizes and depths are based on the results here and on recent velocity and density models [e.g., Anderson, 1967]. The table shows calculated values for the reflectivity at each discontinuity, the $P^{\prime} d P^{\prime}$ amplitude normalized by the maximum amplitude reflection (which is from the ocean bottom), and the lead time from the maximum amplitude reflection. The normalized amplitudes show that the shallow structures spread out the 'surface' reflection energy, thus decreasing the maximum amplitude. This effect causes the 630$\mathrm{km}$ discontinuity (8 and $10 \%$ density and velocity change) in the model to show amplitudes that are $12 \%$ of the maximum main phase. Energy attenuation and interference effects are not included in the model, but may be important. The effect of low $Q$ in the lowvelocity zone would increase the normalized amplitudes below $130 \mathrm{~km}$ by about $10 \%$. Constructive-destructive interference due to the ocean-surface reflection as a function of water depth might cause large variations in the main amplitude reflection and, thus, in normalized amplitudes.

The normalized amplitudes from the records range from 0.30 to 0.50 for depths above 100 $\mathrm{km}$, and deeper reflection amplitudes are of the order of 0.10 . Comparison of these amplitudes 
Perpendicular Distance from $A-A^{\prime}$

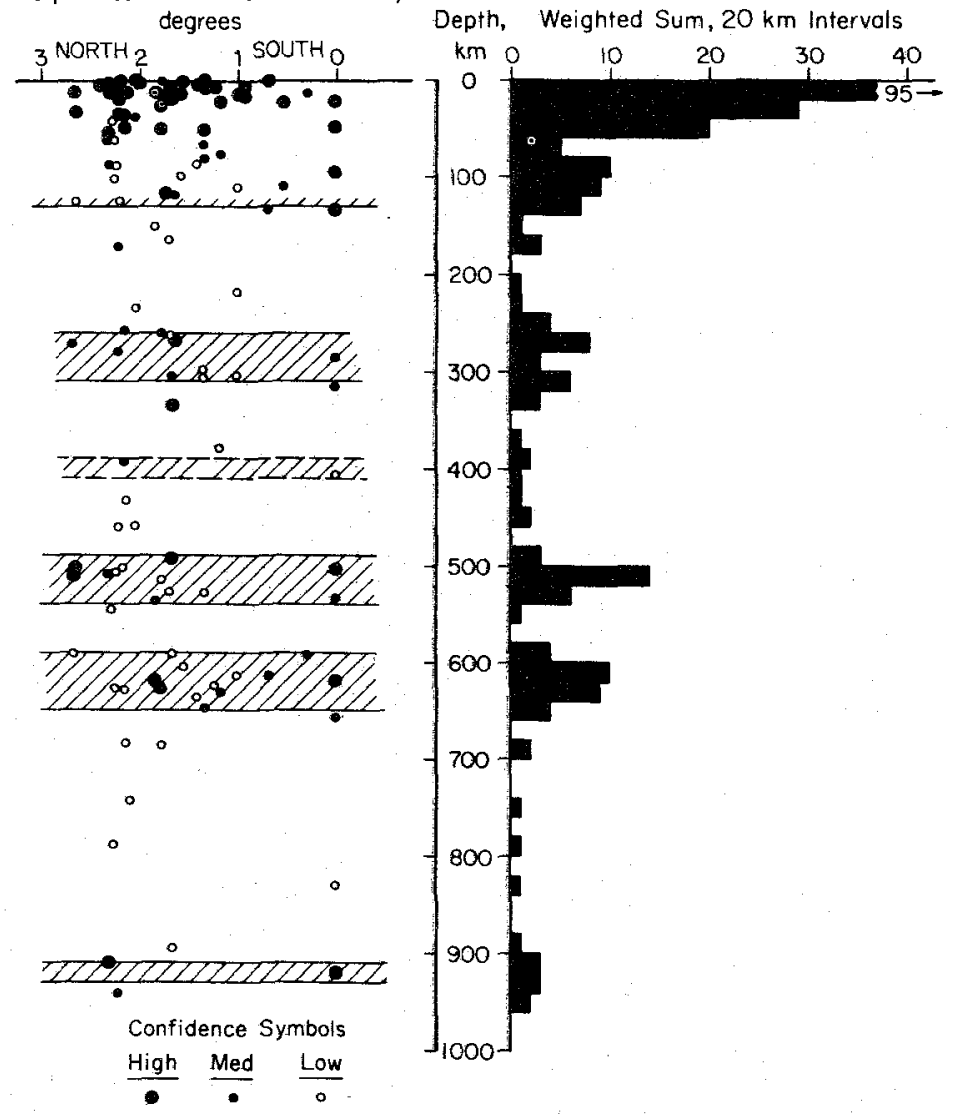

Perpendicular Distance from B-B', degrees Depth, Weighted Sum, $20 \mathrm{~km}$ Intervals 5 pendicular Distance from $\mathrm{B}-\mathrm{B}$, degrees Depth,

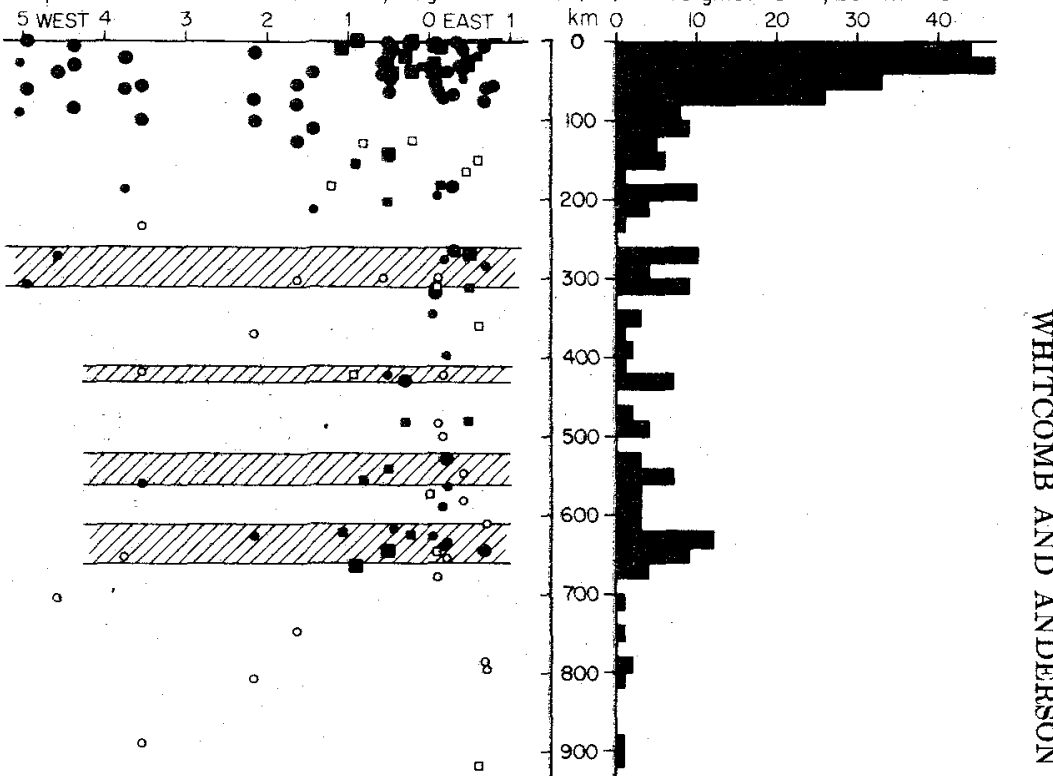

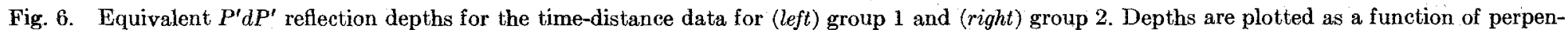

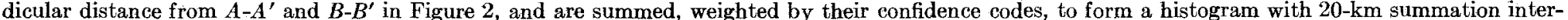
vals. In group 2 , superposition of data necessitated different symbols (squares) to distinguish the northern events 7 , 9 , and 10 . 
TABLE 2. Zones of Reflection

\begin{tabular}{cccc}
\hline $\begin{array}{c}\text { Group 1 } \\
\text { (Atlantic-Indian Rise), } \\
\mathrm{km}\end{array}$ & $\begin{array}{c}\text { Group 2 } \\
\text { (Ninety-East Ridge), } \\
\mathrm{km}\end{array}$ & $\begin{array}{c}\text { Difference } \\
\text { (Group 2-Group 1), } \\
\mathrm{km}\end{array}$ & $\begin{array}{c}\text { Zone } \\
\text { Designation, } \\
\mathrm{km}\end{array}$ \\
\hline 260 & 260 & 0 & \\
310 & 310 & 0 & \\
$(390)$ & $(410)$ & & \\
$(410)$ & $(430)$ & & \\
490 & 520 & +30 & 520 \\
540 & 560 & +20 & \\
590 & 610 & +20 & 630 \\
650 & 660 & +10 & \\
910 & 940 & +30 & 940 \\
930 & 960 & +30 & \\
\hline
\end{tabular}

with the model shows that a first-order discontinuity model is a reasonable approximation to upper-mantle structure for periods of about 1 to 2 sec. The shallow reflections, especially from around $50 \mathrm{~km}$, show higher amplitudes than the model, and the velocity and/or density contrasts at these levels must be considerably larger than $6 \%$. A calculation of the reflection amplitudes from transition zones (Paul Richards, personal communication, 1969) indicates that the reflections observed in this study require transition zone thicknesses of $4 \mathrm{~km}$ or less.

\section{Phase Changes in the Mantle}

Figure 7 shows the major reflecting horizons found in this study and, for comparison, two recent compressional velocity structures determined by refraction techniques [Johnson, 1967;
Julian and Anderson, 1968]. Also shown are velocities predicted for predominately olivine mantles of various compositions in the 'olivine,' 'spinel,' 'post-spinel,' and transition regions adopted from Anderson [1967]. The forsteritefayalite ratios given on the 'theoretical' curves were initially derived by a straightforward application of Birch's [1961] velocity-density relation. The compositions for the present curves were estimated by two different techniques. In the first, the change of compressional velocity with density through solid-solid phase changes was assumed to follow the linear trend established by data for forsterite, spinel, periclase, and corundum, all of which have nearly the same mean atomic weight. The compressional velocity-density relation for iron substitution was taken from data on olivines and

TABLE 3. $\quad P^{\prime} P^{\prime}$ Reflections from a Hypothetical First-Order Discontinuity Model of an Oceanic Upper Mantle

\begin{tabular}{ccrccccc}
$\begin{array}{c}\text { Discontinuity } \\
\text { Depth, km }\end{array}$ & $\begin{array}{c}\text { Velocity, } \\
\mathrm{km} / \mathrm{sec}\end{array}$ & $\begin{array}{c}\text { Change, } \\
\%\end{array}$ & $\begin{array}{c}\text { Density, } \\
\mathrm{g} / \mathrm{cc}\end{array}$ & $\begin{array}{c}\text { Change, } \\
\%\end{array}$ & Reflectivity & $\begin{array}{c}\text { Lead Time } \\
\text { from Max. } \\
\text { Ampl., sec }\end{array}$ & $\begin{array}{c}P^{\prime} d P^{\prime} \text { Normalized } \\
\text { Refl. Ampl. }\end{array}$ \\
\hline 0 & $0-1.5$ & $\infty$ & $0-1.0$ & $\infty$ & 1.000 & -2.4 & 0.45 \\
5 & $1.5-5.4$ & 260 & $1.0-2.5$ & 150 & 0.800 & 0 & 1.00 \\
7 & $5.4-6.8$ & 26 & $2.5-2.9$ & 16 & 0.187 & 0.7 & 0.24 \\
12 & $\mathbf{6 . 8 - 8 . 1}$ & 19 & $2.9-3.2$ & 10 & 0.136 & 2.2 & 0.18 \\
50 & $8.1-7.6$ & -6 & $3.2-3.0$ & -6 & 0.064 & 13. & 0.09 \\
130 & $7.6-8.2$ & 8 & $3.0-3.2$ & 7 & 0.070 & 32. & 0.09 \\
280 & $8.2-8.9$ & 9 & $3.2-3.4$ & 6 & 0.071 & 70. & 0.10 \\
520 & $9.5-9.8$ & 3 & $3.6-3.7$ & 3 & 0.029 & 121. & 0.04 \\
630 & $9.8-10.8$ & 10 & $3.7-4.0$ & 8 & 0.087 & 142. & 0.12 \\
940 & $11.1-11.3$ & 2 & $4.4-4.5$ & 2 & 0.020 & 195. & 0.03 \\
\hline
\end{tabular}




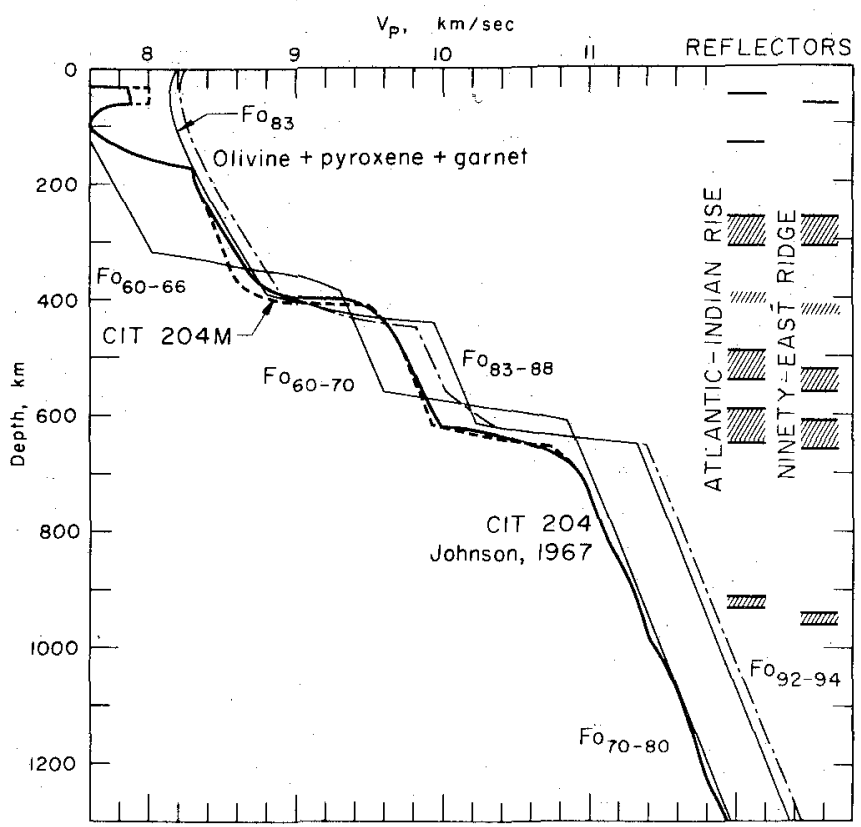

Fig. 7. Comparison of reflecting zones with $P$-wave velocity models (CIT 204M and Johnson [1967]) and with calculated velocities of various mantle compositions.

spinels. The second approach assumed that the elastic constants are unaffected by iron substitution and that the only effect on velocity is through the density.

The solid 'theoretical' 'curves in Figure 7 indicate the positions and shapes of the transition regions between olivine and its spinel polymorph and between the latter and a hypothetical 'post-spinel' structure that is taken to have the mechanical and thermodynamic properties of the oxides $\mathrm{MgO}, \mathrm{FeO}$, and $\mathrm{SiO}_{2}$ (stishovite). The dash-dot curve shows the effect of introducing garnet and pyroxene into the mantle $(\sim 20 \%)$. The pyroxene is assumed to undergo successive transformations to 'spinel' plus stishovite and then to a mixture of the oxides and garnet, which, for present purposes, is assumed not to undergo any phase changes. The effect of the first pyroxene-phase change is to decrease the velocity jump at the 440 -km discontinuity, since pyroxenes are stable to higher pressures than their olivine counterparts, and to increase the total velocity jump across the $630-\mathrm{km}$ discontinuity. In addition, a region of rapid velocity increase sets in above the $630-\mathrm{km}$ discontinuity. Thus, the transition $2\left(\mathrm{Mg}, \mathrm{Fe} \mathrm{SiO}_{3}\right.$ (pyroxene) $\rightarrow(\mathrm{Mg}, \mathrm{Si})_{2} \mathrm{SiO}_{4}$ (spinel) $+\mathrm{SiO}_{2}$ (stishovite) is a possible candidate for the $520-\mathrm{km}$ discontinuity and also provides some of the required features at the $400-$ and $630-\mathrm{km}$ discontinuities (i.e., to spread out the first and sharpen the second). In an olivine-pyroxene mantle with the type of phase changes discussed above, both components break down near $600 \mathrm{~km}$. As is discussed below, the phase change from pyroxene to spinel plus stishovite may be completely or partially preempted by solid solution of pyroxene into garnet.

It has recently been discovered [Ringwood, 1969; Ringwood and Major, 1970; and Akimoto, 1969] that magnesium-rich olivine transforms at high pressure to a distorted spinel-like structure, $\beta$ spinel, with a density increase of about $71 / 2 \%$ instead of to a true spinel structure, which is $10 \%$ denser than olivine. The latter transformation is observed in fayalite-rich olivines. The details of the phase diagram of the system $\mathrm{Mg}_{2} \mathrm{SiO}_{4}-\mathrm{Fe}_{2} \mathrm{SiO}_{4}$ are uncertain at the high pressure forsterite end, but it is probable that the $\beta$ spinel transforms to a true spinel structure at higher pressures; Figure 8 is a phase diagram modified from Ringwood and Major [1970]: Temperature is taken to vary with 


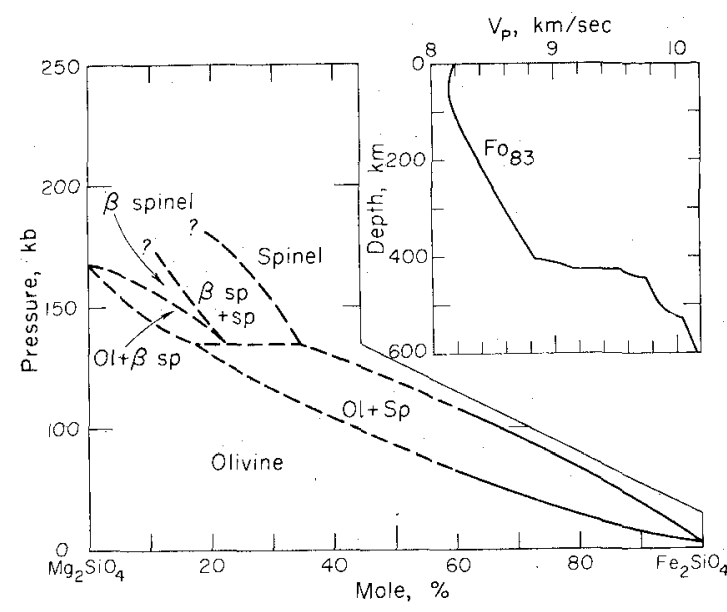

Fig. 8. Phase relations in the system $\mathrm{Mg}_{2} \mathrm{SiO}_{4}$ $\mathrm{Fe}_{2} \mathrm{SiO}_{4}$ modified from Ringwood and Major [1970].

pressure according to a representative geotherm. The intervention of the $\beta$ spinel field complicates the $410-\mathrm{km}$ discontinuity, as is shown in the insert, and introduces a small discontinuity near $520 \mathrm{~km}$. Thus, there is another candidate for the $520-\mathrm{km}$ discontinuity and another source for spreading out the 410 $\mathrm{km}$ transition region. If the fayalite content of the mantle is greater than about 17 mole \%, the phase diagram predicts a first-order seismic discontinuity near $400 \mathrm{~km}$. Earlier phase diagrams, involving only solid solution between olivine and spinel, predicted a second-order seismic discontinuity. The new phase diagram, depending on the fayalite content and on the location of the $\beta$.spinel + spinel field, will lead to 1 or 2 second-order transition regions, each with 2 second-order discontinuities (changes in slope at the top and bottom of the region) or up. to 3 transition regions and 1 first-order discontinuity: Data from this study indicate that a first-order discontinuity at this depth, if present, is small.

Ringwood [1967] discovered that pyroxene will form extensive solid solutions with garnet at pressures of the order of $100 \mathrm{~kb}$ at $1000^{\circ} \mathrm{C}$. If the mantle contains $8-10 \% \quad \mathrm{Al}_{2} \mathrm{O}_{3}$ (relative to pyroxene), the entire pyroxene component of the mantle can be transformed to the garnet structure, and this will proceed to completion slightly before the onset of the olivine-spinel or olivine- $\beta$ spinel transformation. A $10 \%$ density increase of the pyroxene component of the mantle is involved. If there is insufficient $\mathrm{Al}_{2} \mathrm{O}_{3}$, or garnet, for the process to go to completion, there will be pyroxene left over for other pyroxene phase changes such as that discussed above. This pyroxene-garnet transformation, if not preempted by other transformations, will introduce a discontinuity around 300 $\mathrm{km}$.

Some of the following reactions are probably involved in the discontinuities near $630 \mathrm{~km}$ :

$\mathrm{Mg}_{2} \mathrm{SiO}_{4}$ (spinel or $\beta$ spinel)

$\rightarrow \mathrm{MgO}+\mathrm{MgSiO}_{3}$ (ilmenite)

$\rightarrow 2 \mathrm{MgO}+\mathrm{SiO}_{2}$ (stishovite)

$\rightarrow \mathrm{Mg}_{2} \mathrm{SiO}_{4}$ (strontium plumbate or nickel arsenide)

$\mathrm{MgSiO}_{3}$ (pyroxene)

$\rightarrow \mathrm{MgSiO}_{3}$ (ilmenite or perovskite)

$\rightarrow \mathrm{MgO}+\mathrm{SiO}_{2}$ (stishovite)

$\mathrm{Mg}_{2} \mathrm{SiO}_{4}$ (spinel or $\beta$ spinel) $+\mathrm{SiO}_{2}$ (stishovite) $\rightarrow 2 \mathrm{MgSiO}_{3}$ (ilmenite) (if excess $\mathrm{SiO}_{2}$ exists in the transition region)

Several discontinuities deeper than the 630$\mathrm{km}$ zone are indicated. Zones at 940 and possibly $1250 \mathrm{~km}$ are found in this study, and discontinuities at $800,970,1220$, and $1520 \mathrm{~km}$ were found by Johnson. [1969]. Some of the phase transformations mentioned above may occur at the appropriate depths, and there are other possibilities. If the garnet phases of the mantle are not involved in reactions occurring near $630 \mathrm{~km}$, they may survive and be responsible for one or more of the deeper discontinuities. The pyrope-rich component of garnet may transform to an ilmenite structure, and the calcium-rich component may transform to the perovskite structure [Ringwood, 1969]. An alternate transformation is a disproportionation to the component oxides. The latter was estimated by Mao et al. [1969] to occur below $900 \mathrm{~km}$. The ion $\mathrm{Fe}^{+2}$, normally in the high-spin state, will transform to the low-spin state at a pressure and temperature equivalent to a depth of about $1400 \mathrm{~km}$ [Strens, 1969]. In ferromagnesium silicates, this spin-spin phase change involves a density increase of $1-3 \%$. Johnson's [1969] discontinuity at $1520 \mathrm{~km}$ is the most likely candidate for this transition.

A number of phase changes or changes in mineralogy have been proposed for the region 
of the mantle above $100 \mathrm{~km}$. These include: plagioclase $\rightarrow$ aluminous pyroxene $\rightarrow$ pyroperich garnet + low-aluminum pyroxene, spinel + orthopyroxene $\rightarrow$ garnet, quartz + olivine $\rightarrow$ pyroxene, dehydration of amphibolite, ferromagnetic phase changes, and partial melting. Changes of composition, particularly at the Moho discontinuity, are also likely. Some of the upper-mantle candidate phase transformations are listed below, along with estimates of their depth of occurrence [e.g., Ringwood, 1969].

$$
\begin{aligned}
& \text { Amphibole dehydration } \\
& x \mathrm{MgAl}_{2} \mathrm{O}_{4}+(1+x) \mathrm{MgSiO}_{3} \\
& \rightarrow \mathrm{MgSiO}_{3} x \mathrm{Al}_{2} \mathrm{O}_{3}+x \mathrm{Mg}_{2} \mathrm{SiO}_{4} \\
& 4 \mathrm{MgSiO}_{3}+\mathrm{MgAl}_{2} \mathrm{O}_{4} \\
& \rightarrow \mathrm{Mg}_{3} \mathrm{Al}_{2} \mathrm{Si}_{3} \mathrm{O}_{12}+\mathrm{Mg}_{2} \mathrm{SiO}_{4} \\
& 3 \mathrm{MgSiO}_{3} \cdot x \mathrm{Al}_{2} \mathrm{O}_{8} \\
& =x \mathrm{Mg}_{3} \mathrm{Al}_{2} \mathrm{Si}_{3} \mathrm{O}_{12}+3(1-x) \mathrm{MgSiO}_{3} \quad 80-90 \\
& \text { Partial melting }
\end{aligned}
$$

Anderson and Sammis [1969] have argued that the low-velocity zone is due to partial melting. If this is true, the top and bottom of the low-velocity zone should be good reflectors because of the large velocity decrease associated with the presence of a small amount of melt [Spetzler and Anderson, 1968].

\section{Conclusions}

The precursors, illustrated as depth plots and histograms (Figure 6), show significant depth zones for both groups but especially for group 1. (Atlantic-Indian rise) when interpreted as $P^{\prime} d P^{\prime}$ arrivals. There is a one-to-one correlation of depth zones from group 1 to group 2 below $200 \mathrm{~km}$ which itself is significant when we consider that (1) the data are sampled from a narrow (group 1) and a broad (group 2) range of epicentral distances, (2) the focal depths vary widely, and (3) the $P^{\prime} P^{\prime}$ phases for each group reflect at widely separated locations on the earth. The same kind of distribution from another seismic phase is difficult to get, unless the phase has a negative apparent slowness of $1.6-2.3 \mathrm{sec} / \mathrm{deg}$. Because no phases in this time-distance range with the proper apparent slowness have been discovered or proposed as yet, it is concluded that the precursors are deep reflections of the $P^{\prime} P^{\prime}$ phase $\left(P^{\prime} d P^{\prime}\right)$

There is not enough control of shallow struc- ture at the reflecting sites or the $P^{\prime}$ phase near the focus to interpret the data corresponding to depths less than $50 \mathrm{~km}$, but significant variations are seen. At 50 and $130 \mathrm{~km}$ north of the Atlantic-Indian rise, strong reflectors are seen that could be the top and bottom of the lowvelocity zone, particularly if this zone is due to partial melting. These depths are also close to the boundaries of the garnet + aluminous pyroxene stability field [Ringwood, 1969]. This field occurs between the fields of pyroxene + spinel pyrolite and garnet pyrolite. Between 50 and $250 \mathrm{~km}$ at the Ninety-East ridge; structure is more complicated, with a reflector at $100 \mathrm{~km}$ to the west perhaps deepening to the east and a reflector at 60 to $70 \mathrm{~km}$ and about $200 \mathrm{~km}$ under the ridge. Below $250 \mathrm{~km}$ at both locations the reflecting zones, in order of confidence and strength, are: $630,280,520,940$, and $410 \mathrm{~km}$ (very weak). No systematic lateral variation of reflection depth can be seen (the $280-\mathrm{km}$ zone at the Atlantic-Indian rise may be an exception).

The reflection zones below $500 \mathrm{~km}$ show a consistent depth difference between reflection areas of about $20 \mathrm{~km}$; Atlantic-Indian rise zones appear shallower than Ninety-East ridge zones. The most attractive explanations for this difference are (1) that temperatures under the Atlantic-Indian rise are higher, implying that phase changes below $500 \mathrm{~km}$ have negative slopes on phase equilibrium curves or (2) that the $\mathrm{Fe}$ content under the Atlantic-Indian rise is about $8 \%$ higher due to the upwelling of lower mantle material that is richer in Fe.

Amplitudes, normalized by the maximum $P^{\prime} P^{\prime}$ amplitude read on the record, range from 0.30 to 0.50 for reflection depths less than $100 \mathrm{~km}$ and are of the order of 0.10 or less for the deeper reflectors. Simple calculations with only first-order discontinuities for a typical oceanic, upper-mantle model show that a firstorder model is a reasonable approximation to upper mantle structure for periods of about 1 to 2 sec.

The $280-\mathrm{km}$ discontinuity may represent the onset of solid solution of pyroxene into garnet [Ringwood, 1967]. The $410-\mathrm{km}$ discontinuities are almost certainly caused by collapse of the olivine part of the mantle to the $\beta$ spinel or spinel structures. Because reflections from the $410-\mathrm{km}$ discontinuity are so weak, the discon- 
tinuity is probably more spread out than the others, which can be caused by phase-change complications of pyroxenes or olivine to $\beta$ spinel. The $520-\mathrm{km}$ discontinuity could be the transition $\beta$ spinel $\rightarrow$ spinel or the transformation enstatite $\rightarrow$ spinel + stishovite. The 630 $\mathrm{km}$ discontinuity probably involves a major coordination change of most of the silicon into octahedral coordination. The garnet part of the mantle is probably stable to much higher pressures, and its transition to a denser phase may be responsible for the $940-\mathrm{km}$ discontinuity.

Acknowledgments. Discussions with Dr. Paul Richards on reflectivity have been extremely helpful. The University of California at Berkeley kindly made their data available to us.

This research was supported by the Air Force Office of Scientific Research, Office of Aerospace Research, United States Air Force, under contract AFOSR (F44620-69-C'-0067).

\section{REFERENCES}

Adams, R. D., Early reflections of $P^{\prime} P^{\prime}$ as an indication of upper mantle structure, Bull. Seimol. Soc. Amer., 58, 1933, 1968.

Adams, R. D., and M. J. Randall, The fine structure of the earth's core, Bull. Seismol. Soc. Amer., 54, 1299, 1964.

Akimoto, S., High-pressure transformations in $(\mathrm{MgFe})_{2} \mathrm{SiO}_{4}$ olivine, $(\mathrm{MgFe}) \mathrm{SiO}_{3}$ pyroxene and other silicates, paper presented at International Symposium on Phase Transformations and the Earth's Interior, International Upper Mantle Committee, Canberra, 1969 ,

Anderson, D. L., Phase changes in the upper mantle, Science, 157, 1165, 1967.

Anderson, D. L., and B. R. Julian, Shear velocities and elastic parameters of the mantle, $J$. Geophys. Res., 74, 3281, 1969.

Anderson, D. L., and C. Sammis, Partial melting in the upper mantle, unpublished manuscript, 1969.

Anderson, D. L., and M. N. Toksöz, Surface waves on a spherical earth, 1, Upper mantle structure from Love waves, J. Geophys. Res., 68, 3483, 1963.

Archambeau, C. B., E. A. Flinn, and D. G. Lambert, Fine Structure of the upper mantle, $J$. Geophys. Res., 74, 5825, 1969.

Birch, F., Composition of the earth's mantle, Geophys. J., 4, 295, 1961.

Bolt, B. A., Estimation of $P K P$ travel times, Bull. Seismol. Soc. Amer., 58, 1305, 1968.

Bolt, B. A., M. O'Neill, and A. Qamar, Seismic waves near $110^{\circ}$ : Is structure in core or unner mantle responsible?, Geophys. J., 16, 475, 1969.

Engdahl, E. R., and E. A. Flinn, Remarks on the paper 'Early reflections of $P^{\prime} P$ ' as an indication of upper mantle structure,' by R. D. Adams, Bull. Seismol. Soc. Amer., 59, 1415, $1969 a$.

Engdahl, E, R., and E. A. Flinn, Seismic waves reflected from discontinuities within the upper mantle, Science, 163, 177, $1969 b$.

Francis, T. J. G., and R. W. Raitt, Seismic refraction measurements in the southern Indian ocean, J. Geophys. Res., Y2, 3015, 1967.

Green, R. W. E., and A. L. Hales, The travel times of $P$ waves to $30^{\circ}$ in the central United States and upper mantle structure, Bull. Seismol. Soc. Amer., 58, 267, 1968.

Gutenberg, B., Waves reflected at the 'surface' of the earth: P'P'P'P', Bull. Seismol. Soc. Amer., $60,71,1960$

Hoffman, J. P., J. W. Berg, Jr., and K. L. Cook, Discontinuities in the earth's upper mantle as indicated by reflected seismic energy, Bull. Seismol. Soc. Amer., 51, 17, 1961.

Ibrahim, A. K., and O. W. Nuttli, Travel-time curves and upper mantle structure from longperiod S waves, Bull. Seismol. Soc. Amer., 57, $1063,1967$.

Johnson, L. R., Array measurements of $P$ velocities in the upper mantle, J. Geophys. Res., 7\%, $6309,1967$.

Johnson, L. R., Array measurements of $P$ velocities in the lower mantle, Bull. Seismol. Soc. Amer., 59, 973, 1969.

Julian, B. R., and D. L. Anderson, Travel times, apparent velocities and amplitude of body waves, Bull. Seismol. Soc. Amer., 58, 339, 1968.

LePichon, X., and J. R. Heirtzler, Magnetic anomalies in the Indian Ocean and sea-floor spreading, J. Geophys. Res., 78, 2101, 1968.

Lewis, B. T. R., and R. B. Meyer, A seismic investigation of the upper mantle to the west of Lake Superior, Bull. Seismol. Soc. Amer., 58, $565,1968$.

Mao, H. -K., T. Takahashi, W. A. Bassett, J. S. Weaver, and S. Akimoto, Effect of pressure and temperature on the molar volumes of mustite and of three (Fe-Mg) SiO $_{4}$ spinel solid solutions, J. Geophys. Res., 74, 1061, 1969.

Niazi, M., Use of source arrays in studies of regional structure. Bull, Seismol. Soc. Amer., 59, $1631,1969$.

Niazi, M., and D. L, Anderson, Upper mantle structure of western North America from apparent velocities of $P$ waves, $J$. Geophys. Res., 70, 4033, 1965.

Ringwood, A. E., The pyroxene-garnet transformation in the earth's mantle, Earth Planet. Sci. Lett., 2, 255, 1967.

Ringwood; A. E., Phase transformations in the mantle, Eorth Planet. Sci. Lett., 5, 401, 1969.

Ringwood, A. E., and A. Major, The system $\mathrm{Mg}_{2} \mathrm{SiO}_{4}-\mathrm{Fe}_{2} \mathrm{SiO}_{4}$ at high pressures and temperatures, Phys. Earth. Planet. Interiors, 3, 89, 1970.

Spetzler, H., and D. L. Anderson, The effect of temperature and partial melting on velocity and attenuation on a simple binary system, J. Geophys. Res., 79, 6051, 1968. 
Strens, R. G. J., The nature and geophysical importance of spin pairing in minerals of iron (II), The Application of Modern Physics to the Earth and Planetary Interiors, edited by S. K. Runears, p. 213, Interscience, New York, 1969. Whitcomb, J. H., and D. L. Anderson, Reflections from upper mantle discontinuities (abstract), Trans. $A G U, 49,716,1968$.

(Received January 30, 1970; revised April 20, 1970.) 